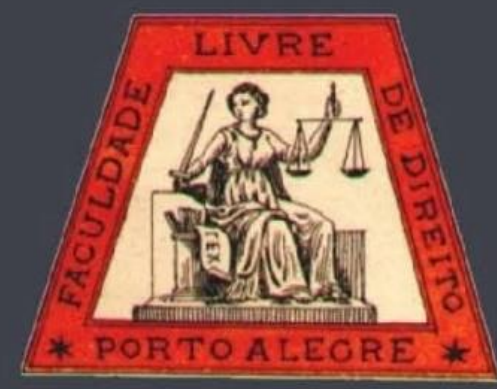

Realidade hegemônica e universalismo europeu: a colonialidade do poder

Hegemonic reality and European universalism: the coloniality of power

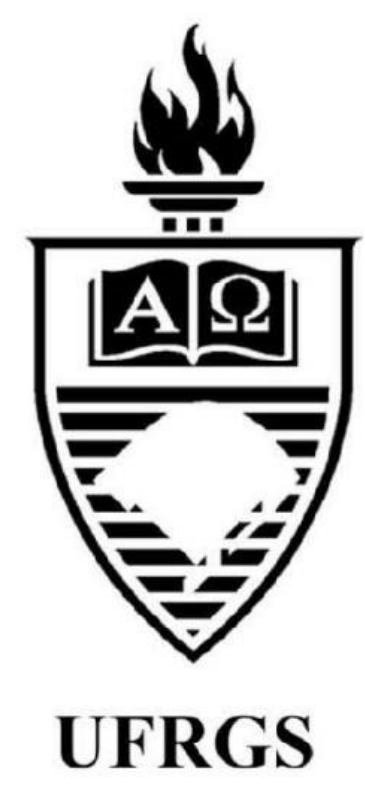

Ingrid Freire Haas

IBMEC 


\title{
Realidade hegemônica e universalismo europeu: a colonialidade do poder
}

\author{
Ingrid Freire Haas*
}

\section{REFERÊNCIA}

HAAS, Ingrid Freire. Realidade hegemônica e universalismo europeu: a colonialidade do poder. Revista da Faculdade de Direito da UFRGS, Porto Alegre, n. 37, p. 99-115, dez. 2017.

\begin{abstract}
RESUMO
O Eurocentrismo marcou o que conhecemos como "modernidade": aniquilou culturas, codificou raças, somatizou as diferenças, impactos sofridos por todos os povos colonizados até hoje, o que chamamos de colonialidade. Neste processo de descobrimento, depois de reconhecido o território colonizado, passavam ao controle e dominação das pessoas, com a justificativa de pacificálas, de apresentá-las a civilização, a salvação. A modernidade significava a Europa e, nessa perspectiva as relações se tornaram binárias, o que era desenvolvido de um lado e o resto, o que era primitivo, de outro, caracterizado pelas diversas "raças". Os povos colonizados foram inseridos na modernidade de forma a desacreditar em qualquer forma de mudança, em qualquer pensamento que não participe da lógica europeia, linear e ocidental. Ao reproduzir conceitos e prerrogativas externas, homogeinizadoras, modernas e ocidentais, o indivíduo esquece de seu próprio ser, sua própria raiz aniquilada e encoberta ao longo de tantos anos pelo colonialismo e que ainda refletem a colonialidade, ilustrado pelo caso concreto de feitiçaria vivido por Moçambique. Desta forma, as últimas décadas do século $\mathrm{XX}$ foram marcadas pela consciência social de grupos étnicos em que a sociedade internacional e seus organismos passaram a reconhecer a pluralidade de culturas e a política multicultural se instalou com a perspectiva de reconhecimento da diversidade cultural existente entre os povos.
\end{abstract}

PALAVRAS-CHAVE

Eurocentrismo. Hegemonia. Colonialidade. Modernidade.

\begin{abstract}
Eurocentrism marked what we know as "modernity": it annihilated cultures, codified races, somatized the differences, impacts suffered by all the peoples colonized until today, what we call coloniality. In this process of discovery, after having recognized the colonized territory, they came to the control and domination of the people, with the justification of pacifying them, of presenting them to civilization, to salvation. Modernity meant Europe, and in this perspective relations became binary, which was developed on the one hand and the rest, primitive on the other, characterized by the various "races." The colonized peoples were inserted in the modernity in order to discredit in any form of change, in any thought that does not participate of the European, linear and western logic. By reproducing external, homogenizing, modern and western concepts and prerogatives, the individual forgets his own being, his own root annihilated and concealed over so many years by colonialism, and which still reflect coloniality, illustrated by the concrete case of witchcraft experienced by Mozambique. Thus, the last decades of the twentieth century were marked by the social conscience of ethnic groups in which the international society and its organisms came to recognize the plurality of cultures and the multicultural politics settled with the perspective of recognition of the cultural diversity existing among the peoples.
\end{abstract}

\section{KEYWORDS}

Eurocentrism. Hegemony. Coloniality. Modernity.

\section{SUMÁRIO}

1. Introdução. 1.1. O Encobrimento das culturas pela chamada "Modernidade". 2. Epistemologias do Sul: a Colonialidade do Poder. 3. A Realidade Hegemônica e o Universalimo Europeu. Considerações Finais. Referências.

\footnotetext{
* Doutora e Mestre em Direito Público pela Pontifícia Universidade Católica de Minas Gerais (PUC-MG). em Sociologia pela Universidade Federal do Ceará (UFC). Professora do IBMEC de Minas Geriais.
} 


\section{INTRODUÇÃO}

Os últimos 500 anos foram marcados pela chamada "modernidade", era de ocultamento das diversas culturas do mundo, que se iniciou com o processo de colonização das Américas, caracterizado pela uniformização dos valores, homogeinização dos saberes pelos países considerados "desenvolvidos".

O processo de aculturação que iniciou-se há anos, desde o início da chamada "modernidade" e permanece até hoje, neste início de século XXI, onde ainda pode-se observar culturas sendo subjugadas, oprimidas e ocultadas em todos os continentes do planeta a todo instante, sempre sob um viés ideológico uniformizante e globalizador balizado pela cultura europeia e também pela norte-americana. A fim de exemplificar com fatos reais, discorrerei sobre um caso concreto, epistemológico, que influenciou e permanece influenciando negativamente culturas ocultadas pela chamada modernidade: os casos de feitiçaria em Moçambique.

Em seguida será analisada a realidade hegemônica e o universalimo europeu presente na sociedade mundial, que oculta as diversas culturas do mundo, mascaradas pela busca do padrão universal ocidental.

1.1 O Encobrimento das culturas pela chamada "Modernidade"

Primeiramente, é importante descrever brevemente sobre o processo de colonização das Américas, a fim de demonstrar como a cultura local indígena foi subjugada, em alguns momentos, em face da cultura ocidental considerada: "moderna".

Para Enrique DUSSEL (1993) o ano de 1492 é a data do nascimento da modernidade. Esta originou-se nas cidades européias medievais, livres, centros de enorme criatividade.

\begin{abstract}
Mas nasceu quando a Europa pôde se confrontar com o seu outro e controlá-lo, vencê-lo, violentálo: quando pôde se descobrir como um "ego" descobridor, conquistador, colonizador da Alteridade constitutiva da própria modernidade. De qualquer maneira, esse Outro não foi "descoberto" como Outro, mas foi "en-coberto" como o "si-mesmo" que a Europa já era desde sempre. De maneira que 1492 será o momento do nascimento da Modernidade como conceito, o momento concreto da "origem" de um "mito" de violência sacrifical muito particular, e, ao mesmo tempo, um processo de en-cobrimento do não europeu. (DUSSEL, 1993, p.8)
\end{abstract}

Esta "modernidade" apresenta-se nestes mais de 500 anos marcados pela ocultação das culturas não europeias, na identificação do "Outro" como um ser subdesenvolvido necessitado da civilidade própria do branco europeu. Aníbal Quijano aponta alguns dos elementos mais importantes do eurocentrismo:

\begin{abstract}
a) uma articulação peculiar entre um dualismo (pré-capital-capital, não europeu-europeu, primitivo-civilizado, tradicional-moderno, etc.) e um evolucionismo linear, unidirecional, de algum estado de natureza à sociedade moderna europeia;

b) a naturalização das diferenças culturais entre grupos humanos por meio de sua codificação com a idéia de raça; e

c) a distorcida relocalização temporal de todas essas diferenças, de modo que tudo aquilo que é não-europeu é percebido como passado. Todas estas operações intelectuais são claramente interdependentes. E não teriam podido ser cultivadas e desenvolvidas sem a colonialidade do poder. (QUIJANO, 2005, p.116)
\end{abstract}

$\mathrm{O}$ eurocentrismo marcou o que conhecemos como "modernidade": aniquilou culturas, codificou raças, somatizou as diferenças, impactos sofridos por todos os povos colonizados até hoje.

Dussel então propõe um resgate das diversas culturas, buscando uma "filosofia da libertação", que parte do sujeito excluído, dominado, do outro. Da mesma forma, HEGEL 
(1995) defendia o Eurocentrismo, para ele a Europa cristã moderna nada tinha a aprender dos outros mundos, outras culturas. Teria um princípio em si mesma e seria sua plena "realização". Este Eurocentrismo de Hegel estaria definido nos seguintes dizeres: o Norte, Europa (sobretudo Alemanha e Inglaterra) tem um direito absoluto por ser o portador do desenvolvimento, diante de cujo povo todo outro-povo não tem direito.

Dussel descreve que para Habermas e Hegel o descobrimento da América não foi um fator determinante constitutivo da Modernidade, apenas representava a possibilidade de mais riqueza, o que se chamava também por desenvolvimento.

No pensamento de Dussel, a América Latina foi a primeira colônia da Europa Moderna. Neste processo de descobrimento, depois de reconhecido o território colonizado, passavam ao controle e dominação das pessoas: "era necessário pacificá-las." Começava-se a alienação do "Outro" como sujeito de si mesmo, deixou-se de lado a práxis violenta, guerreira de domínio de território para uma "práxis erótica, pedagógica, cultural, política, econômica, do domínio dos corpos pelo machismo sexual, da cultura, de tipos de trabalho, de instituições criadas por uma nova burocracia política, dominação do Outro." (DUSSEL, 1993, p. 51)

Considera-se este encobrimento, como uma ocultação da América Indígena e Negra, baseada em graus de civilização, fundado em um mito de uma linearidade histórica no qual, conforme o pensamento moderno europeu, as culturas deveriam ser hierarquizadas, sendo a europeia a mais desenvolvida e por isso responsável pela hegemônica catequização dos povos originários.

Para Aníbal QUIJANO (2005) a raça foi o primeiro critério fundamental para a distribuição da população mundial nos níveis hierárquicos, divididos em lugares e papéis na estrutura de poder da nova sociedade eurocêntrica. Historicamente, as definições em "raças" significou uma forma nova de legitimar as relações de superioridade e inferioridade entre dominantes e dominados.

\begin{abstract}
Na América, a idéia de raça foi uma maneira de outorgar legitimidade às relações de dominação impostas pela conquista. A posterior constituição da Europa como nova identidade depois da América e a expansão do colonialismo europeu ao resto do mundo conduziram à elaboração da perspectiva eurocêntrica do conhecimento e com ela à elaboração teórica da idéia de raça como naturalização dessas relações coloniais de dominação entre europeus e não europeus. Desde então demonstrou ser o mais eficaz e durável instrumento de dominação social universal, pois dele passou a depender outro igualmente universal, no entanto mais antigo, o intersexual ou de gênero: os povos conquistados e dominados foram postos numa situação natural de inferioridade, e consequentemente também seus traços fenotípicos, bem como suas descobertas mentais e culturais. (QUIJANO, 2005, p.107-108, destaque nosso)
\end{abstract}

Basicamente, a modernidade significava a Europa e, nessa perspectiva as relações se tornaram binárias, o que era desenvolvido de um lado e o resto, o que era primitivo, de outro, caracterizado pelas diversas "raças".

As relações intersubjetivas e culturais entre a
Europa, ou, melhor dizendo, a Europa Ocidental,
e o restante do mundo, foram codificadas num
jogo inteiro de novas categorias: Oriente-
Ocidente,
mágico/míticocientífico, irraciono-civilizado,
tradicional-moderno. Em suma, Europa e não-
Europa. Mesmo assim, a única categoria com a
devida honra de ser reconhecida como o Outro da
Europa ou Ocidente, foi Oriente. Não os índios
da América, tampouco os negros da África. Estes
eram simplesmente primitivos. Sob essa
codificação das relações entre europeu/não- 
europeu, raça é, sem dúvida, a categoria básica. (QUIJANO, 2005, p.111¹)

Com a colonização muitas civilizações e muitos povos tiveram sua identidade cultural escondida por um longo período, como ainda ocorre no Brasil. Como por exemplo, os povos originários presentes no território latinoamericano foram considerados povos inferiores por vários séculos. As culturas foram afetadas por valores culturais e domínios econômicos externos que desestabilizaram tanto a identidade brasileira como a latino-americana, sem adentrar na colonização que ocorreu ao longo de todos os continentes.

Como bem descreve Aníbal QUIJANO (2005), no momento da colonização ibérica, todos os povos encontrados no continente americano, independentemente de sua cultura, história, conquistas, memória e identidade como os: astecas, maias, chimus, aimarás, incas, chibchas, etc. foram reduzidos trezentos anos mais tarde a "índios". Da mesma forma, ocorreu com os povos trazidos pela África, como escravos: achantes, iorubás, zulus, congos, bacongos, etc. que após trezentos anos foram reduzidos a "negros". Essas identidades são raciais, coloniais e negativas.

Todos aqueles povos foram despojados de suas próprias e singulares identidades históricas. (...) Sua nova identidade racial, colonial e negativa, implicava o despojo de seu lugar na história da produção cultural da humanidade. Daí em diante não seriam nada mais que raças inferiores, capazes somente de produzir culturas inferiores. Implicava também sua relocalização no novo tempo histórico constituído com a América primeiro e com a Europa depois: desse momento em diante passaram a ser o passado. Em outras palavras, o padrão de poder baseado na colonialidade implicava também um padrão cognitivo, uma nova perspectiva de conhecimento dentro da qual o não-europeu era o passado e desse modo inferior, sempre primitivo. (QUIJANO, 2005, p.116, destaque nosso)

\footnotetext{
1 Essa perspectiva binária, dualista, de conhecimento, peculiar ao eurocentrismo, impôs-se como mundialmente hegemônica no mesmo fluxo da expansão do domínio
}

Entretanto, mesmo com o processo invasivo colonizador sobre as culturas, algumas conseguiram, se é que se pode chamar, sobreviver, reflorescendo e revigorando-se em variadas expressões, reafirmando sua identidade cultural e buscando promover sua diversidade; outras contudo, não tiveram a mesma sorte.

A América Latina possui uma vasta diversidade cultural de povos e raízes, que se identificam e se complementam demonstrando ao subcontinente uma enorme riqueza cultural e ambiental, que deve ser preservada e fortalecida. A América Latina é apenas um exemplo de continente que viu sua cultura de raiz, ou seja, seu modo de viver, ser massacrado por valores exógenos, impostos pela chamada "modernidade". É um "exemplo de uma raça, como tantas outras, mestiça, com uma cultura sincrética, híbrida, um Estado Colonial, uma economia capitalista dependente e periférica". (DUSSEL, 1993, p.51)

Os povos originários ao serem dominados por uma "conquista espiritual", a doutrina cristã, não compreendiam ao ver sua cultura, seus direitos, sua civilização, seus deuses, negados em nome de um deus que não era seu, estrangeiro, e de uma razão moderna. "É um processo de racionalização da Modernidade: elabora um mito de sua bondade, com o qual justifica a violência e se declara inocente pelo assassinato do outro." (DUSSEL, 1993, p.58)

Há todo um conceito de modernidade que justifica o sofrimento dos atos praticados contra o "Outro", pois neste a modernidade é vista como uma forma de emancipar a razão, trazendo tecnologia e infraestrutura civilizatória; levando aos povos algo inalcançável, a salvação. Desta forma, era justificada como uma ação pedagógica,

colonial da Europa sobre o mundo. (QUIJANO, 2005, p.111) 
ou mesmo, uma violência essencial para que fossem salvos.

Como deve ter sido difícil aos povos originários receber diagnósticos externos de que seu "Deus" não existe, de que seus valores são errados, e que o certo é seguir a cultura branca. Contudo, importante ressaltar a visão de Bartolomeu de Las Casas que foi além do sentido crítico da modernidade como emancipação, assim como Ginés de Sepúlveda, Francisco de Vitória e mais tarde Kant. Para Bartolomeu, deve-se procurar "modernizar" o índio sem destruir sua alteridade. (LAS CASAS, 1991)

Vitória, por exemplo, no ano de 1500, já reconhecia que os índios eram seres humanos, assim como os espanhóis, e deveriam ter sua autonomia e direitos reconhecidos e respeitados, além de deverem se inter-relacionar, por meio do direito internacional público, com os povos cristãos.

\begin{abstract}
Vitória baseado em princípios de direito natural e de direito das gentes, tinha o seguinte pensamento: "todos os homens são iguais, merecem o mesmo tratamento, qualquer que seja sua origem. A pessoa humana tem valor inestimável onde quer que esteja. [...] Vitória contribui para definir um direito internacional do homem - direito internacional privado - a partir dos direitos humanos. Portanto, qualquer ser humano tem direito de se comunicar com outros, de transitar, fixar residência, ter propriedade, trabalho, enfim, direito à integridade pessoal em qualquer lugar do orbe." ( AZEVEDO, 2008, p.156, destaque nosso)
\end{abstract}

A visão de Vitória era a do teólogo que entrelaçou o direito e a ordem moral, tornando clara a sua fundamentação sustentada na base ética. Vitória foi corajoso ao enfrentar o poder do

\footnotetext{
2 "Desde Vitória, o Direito Internacional Público se olvidara de sua principal razão, a proteção dos direitos humanos, para concentrar-se no aspecto de constituir-se como um direito criado pelos Estados para regular suas relações internacionais. [...] Reencontrando sua motivação após à Segunda Guerra mundial, com a Declaração Universal dos Direitos do Homem.” (RUIZ, 2002,p.11;12)
}

Estado em defesa dos direitos humanos dos povos colonizados $^{2}$. Reconhece-se que o mesmo já estaria, inclusive, antecipando o princípio da autodeterminação dos $\operatorname{povos}^{3}$.

\begin{abstract}
Vitória nos teria transmitido a idéia de igualdade e de dignidade, podendo ser considerado o precursor dos direitos humanos. [...] A presença de Vitoria se faria notar inclusive no vocabulário das Nações Unidas quando, por exemplo, se faz referência ao 'patrimônio comum da humanidade' que nada seria do que a idéia do totus orbis e a percepção de um bem comum de todo o orbe, acima do bem comum de partes e Estados particulares. (URDANOZ apud AZEVEDO, 2008, p.201, destaque nosso)
\end{abstract}

Dussel, por exemplo, descreve que Bartolomeu colocou-se ao lado do Outro, acreditando que se a Europa cristã era mais desenvolvida e se quisesse mostrar sua pretensa superioridade, deveria fazê-lo levando em conta a cultura do Outro, respeitando sua alteridade. Grandes nomes que retrataram em sua época uma grandeza ideológica que se faz absolutamente presente na atualidade, uma vez que já reconheciam que a dignidade da pessoa humana deveria se fazer presente em qualquer lugar do mundo.

Neste contexto de perda de cultura e identidade, importante mencionar o quanto algumas religiões existentes no mundo atual ainda profanam o conhecimento de Cristo ou Allah como o único Deus a salvar a humanidade sem tampouco reconhecer e respeitar a diversidade cultural religiosa, na qual cada um tem o direito de ter sua fé, crença, religiosidade ou ainda não crer se for esta a opção individual.

3 Preâmbulo da Declaração sobre o Direito ao Desenvolvimento: "Direito dos povos à autodeterminação, em virtude do qual eles têm o direito de determinar livremente seu status político e de buscar seu desenvolvimento econômico, social e cultural". (ONU,1986) 
Como por exemplo os jornais internacionais ${ }^{4}$ noticiaram em maio de 2014, que no Sudão, um tribunal condenou à morte, uma mulher, Mariam Yahya Ibrahim que ao recusar aderir ao islamismo, optou pelo cristianismo e casou-se com um cristão. Ainda neste sentido, no Brasil, vivenciam-se povos originários que sofrem pela ação de missionários na tentativa de evangelizá-los com a justificativa da necessidade das "Missões Transculturais" em busca da "salvação". Conforme citação abaixo, do ano de 2013, mencionando tribos indígenas que ainda não foram evangelizadas e portanto, desconhecem a chamada "salvação":

1,5 bilhões de pessoas, nunca ouviram do evangelho sequer uma vez. Porém, se falarmos em número de povos, vamos descobrir que da tabela dos 11.874 povos, 3.915 deles nunca ouviram do evangelho. E o que dizer das 240 tribos indígenas brasileiras, das quais 126 não possui presença missionária evangélica, enquanto que 06 tem situação indefinida. Será que estas pessoas não terão o direito de ouvir pelo menos uma vez na vida a mensagem de salvação? (FRANÇA, 2013, destaque nosso)

O que seria salvação? O que significa para uns seria o mesmo para outros? Cada cultura e religião identifica e reconhece determinados significados a sua maneira. Muito triste seria se todos os conceitos e significados fossem iguais, não haveria diversidade nem tampouco aprendizado com o outro, com a outra cultura e sua própria história.

\footnotetext{
${ }^{4}$ Meriam Yehya Ibrahim, sudanesa ortodoxa de 27 anos, casada com um cristão, deu à luz uma menina numa prisão de Cartum, onde está presa com o seu filho de 20 meses. A justiça sudanesa, regida pela lei islâmica (sharia) desde 1983, acusou Meriam de adultério em agosto de 2013, por estar em união com um homem que não é muçulmano. Em fevereiro de 2014, foi acusada de apostasia por ter se afirmado cristã, renunciando à religião do seu país. No dia 15 de maio foi condenada a cem chicotadas por adultério e, por apostasia, à morte por enforcamento. As embaixadas dos Estados Unidos, Reino Unido, Canadá e Holanda divulgaram um comunicado conjunto onde manifestaram a sua "profunda preocupação" com o caso e evocaram o "direito à liberdade de religião" perante o Sudão. Segundo
}

A liberdade religiosa, assim como outros diversos valores e escolhas realizados pelo indivíduo retratam a cultura de determinada região ou até indivíduo. Diretrizes ideológicas que dizem respeito ao indivíduo e mais ninguém, pois tratam diretamente da dignidade da pessoa humana.

Como bem expressa Tatiana Souza (2013, p.17) "Enquanto o Direito Internacional for moderno, apenas será capaz de desenvolver um Estado de Direito Internacional moderno, que, paradoxalmente, não poderá ser universal, porque a modernidade é a expressão de um particular".

Por fim, o continente americano é apenas um exemplo de território que diante ao processo de colonização dos países europeus, vivenciou o massacre de sua cultura sob um viés de que a modernidade civilizatória traduz o desenvolvimento e a salvação dos povos.

\section{EPISTEMOLOGIAS DO SUL: A COLONIALIDADE DO PODER}

A modernidade trouxe uma epistemologia ${ }^{5}$ dominante visando uma suposta universalidade amparada pela uniformização de valores, saberes, culturas, etc. Uma homegeinização dos comportamentos dos povos colonizados que os manteve alienados e encobertos por vários anos.

Para Boaventura trata-se de um “epistemicídio, a supressão dos conhecimentos

o jornal britânico, o pedido de libertação de Ibrahim lançada pela Anistia Internacional tem o apoio de 700 mil pessoas em todo o mundo. As autoridades sudanesas declararam que o cumprimento da sentença de morte de Ibrahim iria ser adiado por dois anos, para que ela possa cuidar da recémnascida. (DN GLOBO..., 2014)

5 "Toda experiência social produz e reproduz conhecimento, e ao fazê-lo, pressupõe uma ou várias epistemologias. Epistemologia é toda noção ou idéia, refletida ou não, sobre as condições do que conta como conhecimento válido". (SOUZA SANTOS, 2010, p.15) 
locais perpetrada por um conhecimento alienígena". (SOUZA SANTOS; MENESES, 2010, p. 16) Aponta que a diversidade epistemológica presente em todo o mundo seria designada por "epistemologias do sul". As epistemologias do Sul são o conjunto de intervenções epistemológicas que denunciam a dominação capitalista e colonial, "uma relação extremamente desigual de saber-poder que conduziu à supressão de muitas formas de saber próprias dos povos e/ou nações colonizadas". (BOAVENTURA; MENESES, 2010, p. 19)

Para Aníbal QUIJANO (2010) o colonialismo difere-se da colonialidade, o primeiro restringe-se a uma estrutura de exploração/dominação política, dos meios de produção e do trabalho por uma população determinada a outra de diferente identidade. Já a segunda, a colonialidade, ainda que vinculada ao colonialismo é mais profunda e duradoura, origina-se na América e é um dos elementos do padrão mundial do poder capitalista que se sustenta na imposição de uma classificação racial/étnica da população do mundo.

A diretriz que é dada aos povos colonizados é apenas uma: "a Europa e os europeus eram o momento e o nível mais avançados no caminho linear, unidirecional e contínuo da espécie”. (QUIJANO, 2010, p. 86)

Os povos colonizados são inseridos na modernidade de forma a desacreditar em qualquer forma de mudança, em qualquer pensamento que não participe da lógica europeia, linear e ocidental.

Tal reprodução está ligada ao conceito de Aníbal Quijano de "Colonialidade do Ser" em que ainda os povos colonizados reproduzem a lógica moderna de que a Europa é melhor. Isso se reflete em todos as esferas da vida em sociedade, na qual, por exemplo, deseja-se estudar no exterior em universidades americanas ou europeias, pois inconscientemente acredita-se na melhor possibilidade de conhecimento. Da mesma forma, quando se compra produtos e serviços importados acreditando que são melhores que os nacionais, etc. Como expressa Maldonado-Torres:

A colonialidade do Ser refere-se ao processo pelo
qual o senso comum e a tradição são marcados
por dinâmicas de poder de caráter preferencial:
discriminam pessoas e tomam por alvo
determinadas comunidades. O caráter
preferencial da violência pode traduzir-se na
colonialidade do poder, que liga o racismo, a
exploração capitalista, o controle sobre o sexo e
o monopólio do saber, relacionando-se com a
história colonial moderna. (QUIJANO apud
MALDONADO-TORRES, 2010, p.423)

Maldonado-Torres descreve que a "colonialidade do Ser sugere que o Ser, de certa maneira, contraria a nossa própria existência" (MALDONADO-TORRES 2010, p. 421). Ao reproduzir conceitos e prerrogativas externas, homogeinizadoras, modernas e ocidentais, o indivíduo esquece de seu próprio ser, sua própria raiz aniquilada e encoberta ao longo de tantos anos pelo colonialismo e que ainda refletem a colonialidade.

Imprescindível descrever o pensamento de Walter Cannon em seu clássico artigo de 1942, denominado Voodoo Death, que identificou nas diferentes colônias, em seus povos nativos, culturas específicas, consideradas feitiçaria pelos povos considerados "civilizados".

Nos registros de antropólogos e outros que viveram com pessoas primitivas em partes amplamente espalhadas do mundo há o testemunho de que, quando submetidos a feitiços ou feitiçaria ou ao uso de "magia negra", homens podem ser mortos. Entre os nativos da América do Sul e África, Austrália, Nova Zelândia e as ilhas do Pacífico, bem como entre os negros do Haiti nas proximidades, a morte "voodoo" foi relatada por observadores aparentemente competentes. O fenômeno é tão extraordinário e tão estranho à experiência de pessoas civilizadas que parece incrível; Certamente, se é autêntico, merece uma atenção cuidadosa. Proponho recitar instâncias deste modo de morte, para saber se os relatórios do fenômeno são confiáveis e para 
examinar uma possível explicação se ele provar ser real. (CANNON, 1942, tradução nossa ${ }^{6}$ )

Cannon em seu texto demonstra exemplos diversos de casos considerados como "magia negra" por povos nativos que foram colonizados.

Neste momento darei como exemplo a experiência vivida pela República de Moçambique, país africano que como tantos outros ainda sofre, na atualidade, reflexos do colonialismo/ colonialidade e os impactos de suas premissas modernas e universalizadoras.

Conforme Maria Paula Meneses (2010) em Moçambique, casos suspeitos de feitiçaria têm adquirido importância nos últimos quinze anos. Considerada uma prática selvagem, tem sido abominada pela racionalidade moderna, com variadas acusações de tráfico de órgãos e contrabando de corpos que nunca se confirmaram. Muitos avaliavam que com a colonização e a chegada da modernidade esta prática tenderia a acabar, contudo o que se observa é uma continuidade em ambientes rurais e urbanos.

O colonialismo possui a característica de aflorar a desordem sobre seus povos nativos, fazendo-os sentir inferiorizados, oprimidos, selvagens inferiores em sua essencialidade.

Assim, o conhecimento científico emergiu como um instrumento da superioridade portuguesa, os saberes do outro, inferior, eram identificados como formas locais de interpretar o mundo e os estudos antropológicos coloniais usavam a feitiçaria para estigmatizar, classificar, e distanciar a África da Europa. (MENESES, 2010)

\footnotetext{
${ }^{6}$ In records of anthropologists and others who have lived with primitive people in widely scattered parts of the world is the testimony that when subjected to spells or sorcery or the use of "black magic" men may be brought to death. Among the natives of South America and Africa, Australia, New Zealand, and the islands of the Pacific, as well as among the negroes of nearby Haiti, "voodoo" death has been reported by apparently competent observers. The phenomenon is so extraordinary and so foreign to the
}

Os povos africanos deveriam se espelhar no europeu que estava trazendo a modernidade e o desenvolvimento; nesta seara, a feitiçaria era sempre vista como selvageria, desordem, inferioridade, bruxaria que deveria ser exterminada.

Para Meneses (2010, p.180) "um dos momentos base da intervenção colonial é a transformação do "outro" num objeto, sobre o qual a ordem de conhecimento colonial poderia exercer o seu poder". Explica que para os ocidentais fatos que seriam explicados como acidentais, doenças, mortes ou qualquer outro infortúnio, é explicado como resultado de feitiçaria, explicações que variam conforme as regiões e as comunidades, tendo como denominador comum sua natureza não previsível ou incontrolável. "A perseguição aos feiticeiros é vista como um costume aberrante e disfuncional ao invés de fazer parte de um sistema espiritual complexo, presente no continente desde há muito". (MENESES, 2010, p. 183)

Assim, considera-se feitiçaria, pelos ocidentais, todas as crenças africanas contrárias às crenças cristãs. Como por exemplo, para os cristãos: acender uma vela pra um santo, ajoelharse, jogar água benta sobre as pessoas e objetos, comungar, cumprir as mais diversas promessas aos chamados milagres, são práticas comuns do cristianismo que podem ser vistas por outra cultura como feitiçaria ou supertição, inferioridade.

São várias as interpretações advindas pelo ocidente sobre uma crença que simplesmente é diversa, trata-se de outra cultura que se

experience of civilized people that it seems incredible; certainly if it is authentic it deserves careful consideration. I propose to recite instances of this mode of death, to inquire whether reports of the phenomenon are trustworthy, and to examine a possible explanation of it if it should prove to be real. (CANNON, 1942) 
confronta com a cristã e por isso passível de vários mal-entendidos.

Meneses aponta que atualmente, com a circulação de ideias, mercadorias, redes mundiais, é possível ver, nas diferentes regiões do país, a mistura de variadas crenças que se expressam das mais diversas formas: rituais locais, tradições muçulmanas, tradições cristãs, cultura ocidental, cultos transnacionais, etc.

Relata ainda, que o país vivencia a miséria, a pobreza, a desordem, e muitas vezes acusações de feitiçaria são dirigidas a pessoas que conquistaram prestígio econômico e social.

\begin{abstract}
As múltiplas tentativas de criminalização das crenças locais atingiram o cerne das ordens sociais e morais africanas. No entanto, através de lutas diárias com a morte, desastres, e contra a discriminação, os Moçambicanos esforçam-se por resistir, apropriar e mudar o sistema ideológico monocultural que quer o estado colonial, quer o Estado contemporâneo, têm procurado impor. (MENESES, 2010, p.247)
\end{abstract}

Moçambique, assim como outros povos colonizados, luta para encontrar sua identidade, busca suas verdadeiras raízes que naturalmente se confrontam e misturam com valores ocidentais que se instalaram há anos pela modernidade. Desta forma, diversos conflitos continuam se instalando mesmo após o fim da colonização, com seus impactos que são intermináveis.

Infelizmente trata-se de uma triste realidade vista em diversos outros países colonizados pelo sistema mundo moderno.

Como bem expressa Boaventura, "as epistemologias do Sul reclamam o recuperar máximo das experiências de conhecimentos do mundo, alargando o espaço de produção de

\footnotetext{
${ }^{7}$ José Luiz Quadros Magalhães descreve que não é a primeira vez que o Jornal Estado de Minas se utiliza deste termo "Nós X Eles", referindo-se a população de rua. "Estamos aí diante de uma equação nós x eles: "nós" "sãos" x "eles" "drogados" ou "nós" "dentro da lei" x eles "criminosos". (MAGALHÃES, 2013....)

${ }^{8}$ Eurocentrism bifurcates the world into the "West and the Rest" and organizes everyday language into binaristic
}

conhecimento e de modos de pensar, instaurando a própria possibilidade de falar com - em vez de falar sobre - outros mundos e saberes". (MENESES, 2010, p.253).

\section{A REALIDADE HEGEMÔNICA E O UNIVERSALISMO EUROPEU}

O Brasil está inserido na sociedade ocidental, capitalista, eurocêntrica, não percebe como a cultura do "Nós X Eles"7 foi absorvida pela história, pelos representantes, pelo sistema educacional, o qual ao longo dos anos ensina que o Ocidente, formado principalmente pela Europa e pelos EUA significa o desenvolvimento, o crescimento econômico, o bem estar social. Apresentando o resto do mundo, quando os apresenta, como países subdesenvolvidos.

"Nós" os civilizados, "eles" os bárbaros; como os países ocidentais moldaram um pensamento hegemônico, padronizado, moderno que faz com que os não ocidentais sejam "eles", os "outros", os selvagens, os subdesenvolvidos, os judeus, os terroristas.

"The West and the Rest", ou seja, "O Ocidente e o Resto" assim Robert Stam e Ella Shohat comentam em seu artigo: "Contested Histories: Eurocentrism, Multiculturalism and the Media," a atuação Eurocêntrica ao longo da história.

\footnotetext{
Eurocentrismo bifurca o mundo entre o "Ocidente e o Resto" e organiza a linguagem cotidiana em hierarquias binárias implícitas para a Europa: as nossas "nações", as suas "tribos", as nossas "religiões", as suas "superstições", a nossa "cultura", o seu "folclore", a nossa "defesa", o seu "terrorismo". (STAM and SHOHAT, 1994, p.296, tradução nossa $)^{8}$
}

hierarchies implicity flattering to Europe: our "nations", their "tribes"; our "religions", their "supersticions"; our "culture", their "folklore"; our "defense", their "terrorism". (STAM, 1994, p. 296) 
Esta bifurcação entre o Ocidente e o Resto está presente na história da humanidade, através do capitalismo. E esta divisão do "Nós X Eles" se alastra pelos continentes, pelos povos, pelas gerações, pelos indivíduos, em que pais indiretamente transmitem aos filhos valores preconceituosos que afloram as diferenças por anos.

Esse distanciamento proposto pelo "Nós X Eles", acontece de forma avassaladora, não apenas de forma ampla na sociedade, mas, sobretudo internamente em cada indivíduo que inconscientemente se pressupõe superior ao pertencer a determinada cultura, que não outra, como por exemplo: "nós" os brancos, "eles" os negros, "nós" os homens, "elas" as mulheres; "nós" os heterossexuais, "eles" os homossexuais; "nós" os letrados, "eles" os analfabetos; "nós" da zona sul, "eles" da zona norte; "nós os ricos, "eles" os pobres; "nós" os cristãos, "eles" os muçulmanos; "nós" os católicos, "eles" os evangélicos; "nós" os jovens, "eles" os velhos e etc., o que não faltam são diferenças infinitas que pode-se citar.

Conforme Charles Mills, "a dominação do mundo pela supremacia branca ou a dominação do mundo pelo Ocidente foi visto como uma prova da superioridade racial branca". (MILLS, 2007, p.91, tradução nossa ${ }^{9}$ )

Superioridade branca que pode-se considerar apenas como econômica, uma vez que não deveria haver hierarquia ou superioridade entre os indivíduos baseada em raça, credo ou cor.

Immanuel Wallerstein (2007) apresenta em sua obra: "O Universalismo Europeu - a retórica do poder" como, desde o século XVI, a legitimidade ocidental ao longo da história,

\footnotetext{
9 "The domination of the world by the White supremacist in which The domination of the world by the West was seen as proof of White racial superiority." (MILLS, 2007, p. 91) 10 Com a doutrina do direito à ingerência e, consequentemente, da soberania limitada, o que os Estados Unidos e certos países da União Europeia - o centro do sistema capitalista mundial - tratam de derrogar, em nome
}

buscou aplicar em um primeiro momento, o do colonialismo, doutrinas cristãs consideradas civilizatórias, justificadas pela evangelização e pela "modernidade" aos povos colonizados.

Já na segunda metade do século XX, caracterizada pela descolonização, a consagração da Organização das Nações Unidas e suas agências especializadas, marcaram uma mudança na dinâmica do poder ocidental, regidos em princípios como da Não Intervenção; Autodeterminação dos Povos; Igualdade soberana de todos os povos; Boa-fé, Proibição do uso da força, etc.

Com o fim da Segunda Guerra Mundial e a necessidade de reconstrução das relações internacionais baseadas no objetivo comum de manutenção da paz, a ONU, após o fracasso da anterior Liga das Nações, surge como uma forma de viabilizar os princípios acima expostos.

Assim, no período pós-colonial, Wallerstein descreve que a linguagem da retórica do poder passou a ter um novo significado e força, os chamados: Direitos Humanos.

Para Wallerstein (2007), o sistema capitalista ${ }^{10}$ regido principalmente pelos Estados Unidos e alguns países da Europa, apresenta ao mundo valores distorcidos, conhecidos como universais, o que ele denomina de "universalismo europeu", na tentativa de defender interesses hegemônicos desse sistema-mundo moderno, que são três:

O primeiro defende Direitos Humanos, e
promove uma coisa chamada "democracia";
o segundo acompanha o jargão do choque entre
civilizações, no qual sempre se pressupõe que a
civilização ocidental é superior às "outras"
civilizações porque é a única que se baseia nesses
valores e verdades universais. E o terceiro é a
afirmação da verdade cientifica do mercado, do

de valores universais, que na realidade não existem, são os dois princípios essenciais em que se fundamenta a frágil estrutura do Direito Internacional, desde a Paz de Westphalia, em 1648: a soberania nacional e igualdade legal das nações. (WALLERSTEIN, 2007, p.20) 
conceito de que "não há alternativa" para os governos senão aceitar e agir de acordo com as leis da economia neoliberal. (WALLERSTEIN, 2007, p.26, destaque nosso)

Assim, os primeiros seriam, no pósSegunda Guerra, os direitos humanos e a chamada democracia ${ }^{11}$ apresentados como valores a serem instituídos, defendidos e seguidos por todos os Estados a fim de se alcançar a tão sonhada dignidade da pessoa humana, descrita na Carta das Nações Unidas de 1945. Contudo, estes Direitos Humanos, estrategicamente, somente serão defendidos quando convenientes aos países detentores desta hegemonia.

Em seguida, caminhando paralelamente à consagração da universalização dos direitos humanos, o segundo valor apresentado ao mundo de forma distorcida é a suposta superioridade da civilização ocidental sobre todas as outras na defesa de tais valores universais.

Wallerstein critica o pensamento de Samuel Huntington denominado: o "Choque de Civilizações" que pressupõe que a civilização ocidental é superior às "outras" civilizações porque é a única que se baseia nesses valores e verdades universais.

A principal ideia de Huntington é de que a cultura e as identidades culturais são as identidades das próprias civilizações e são elas que ordenam e padronizam as tensões, os conflitos, as semelhanças, a coesão e a desintegração no mundo pós-Guerra Fria.

Huntington relatou no final do século XX que, "pela primeira vez na história, a política mundial se tornou multipolar e multicivilizacional" (HUNTINGTON, 1997, p.19). A crescente modernização econômica do Oriente diminuiu a influência do Ocidente, desestabilizando o até então equilíbrio de poder dos ocidentais.

\footnotetext{
11 A democracia vivenciada pelos países ocidentais na atualidade concentra-se no voto majoritário: "O voto, confundido muitas vezes com a própria ideia de democracia, é na verdade um instrumento de decisão, ou de interrupção
}

E pondera que a sobrevivência do Ocidente apenas se daria com a reafirmação norte-americana de sua identidade ocidental, além de aceitarem que "sua civilização é singular e não universal”. (HUNTINGTON, 1997, p.19)

\begin{abstract}
No mundo pós Guerra Fria, as distinções mais importantes entre os povos não são ideológicas, políticas ou econômicas, elas são culturais. Nós só sabemos quem somos quando sabemos quem não somos e, muitas vezes, quando sabemos contra quem estamos. (HUNTINGTON, 1997, p.20, destaque nosso)
\end{abstract}

Huntington acertou quando descreve que as distinções mais importantes entre os povos não são ideológicas, políticas ou econômicas, elas são culturais. Pois uma vez que cada cultura ou cada povo possuir a liberdade de estabelecer seus próprios desejos, os conceitos relativos aos valores ideológicos, políticos ou econômicos irão mudar. Para uma tribo indígena ou para os quilombolas, o que significa desenvolvimento ou crescimento econômico?

Contudo, Huntington não descreveu nem ressaltou a importância do diálogo entre os povos para o desenvolvimento sustentável das nações, o que demonstra a fragilidade de sua teoria, bem como não apresentou soluções aos problemas encontrados pelas civilizações.

E por último, mas não menos importante, o terceiro valor distorcido pelos ocidentais é o de que "não há alternativa" para os governos a não ser o neoliberalismo que se estabelece como o sistema ideal de sustentação do capitalismo e de uma economia de mercado em crescente ascensão global. Assim, outra escolha significaria o fracasso e o anti-crescimento.

Mas pergunta-se: o que significaria efetivamente a palavra universal ou o que se entende por universal? WALLERSTEIN (2007) afirma que os valores universais/globais

do debate, de interrupção da construção do consenso, e logo, um instrumento usado pela "democracia majoritária" para interromper o processo de debate em nome da necessidade de decisão.” MAGALHÃES (2012, p. 41) 
transcritos na atualidade, que incorporam as teorias das organizações e organismos internacionais não são dados, mas sim criados por um conjunto de doutrinas e visões éticas dentro de um contex to europeu. " $O$ argumento paradoxal de que não há nada tão etnocêntrico, tão particularista quanto à pretensão ao universalismo". (WALLERSTEIN, 2007, p. 73)

Interessante como países

ocidentais, regidos pelo sistema capitalista, como a maior parte dos estados da América Latina, por exemplo, absorveram a doutrina do universalismo europeu de forma uniforme e ampla, reconhecendo tais valores como imprescindíveis, necessários e verdadeiros para o alcance dos objetivos regidos pela Carta da ONU de 1945, como a manutenção da paz e igualdade entre as nações.

"Estamos ante a forma mais sutil de hegemonia", nos dizeres de Flores (2013, p.20). Esta sutilidade está presente no globalitarismo e no capitalismo que indiretamente coisificam e fragmentam as relações sociais.

Edgar Morin (2005) descreve o apelo a superação do europeocentrismo, em nome do interesse pela história do resto do mundo e, portanto, pela história de outras culturas, sociedades, modelos de desenvolvimento, rompendo com o dogma de uma evolução unitária e linear da humanidade; uma evolução, que pressupõe a extensão ao resto do mundo do modelo de desenvolvimento da Europa. Descreve que a tarefa de um historiador seria "levar em conta a singularidade de cada cultura, de cada época, de cada modo de desenvolvimento, comparando-os entre eles e pondo em evidência suas inter-relações". (MORIN, 2005, p.365)

\footnotetext{
“O sentimento de ser um centro é constante durante toda a história da Europa. (...) No século $\mathrm{XX}$, vem o tempo da nostalgia traduzida em termos de declínio. A Europa sonha então com sua unidade quando não tem mais o sentimento de ser o centro do mundo. Depois de 1945, dividida, ameaçada, ela tenta ainda, diante dos impérios, afirmar sua existência. A Europa-
}

centro é também um discurso sobre o mundo e um discurso ao mundo que tem vocação para ser universal; mas este discurso é singularmente ambivalente: as palavras de acolhida e de liberdade coexistem com as palavras de exclusão e de intolerância. O discurso civilizador mascara com frequência uma vontade de dominação". (MORIN, 2005, p.365)

MORIN transpõe a necessidade europeia em ser o centro do mundo, mesmo após a segunda guerra mundial, quando dividida, visava afirmar sua existência. A Europa com um discurso civilizador de acolhida e liberdade, mascarava sua real vontade de dominação baseada na exclusão e na intolerância.

Após a Segunda Guerra Mundial e durante a Guerra Fria, os polos de poder que regiam as relações internacionais eram definidos, claros e distanciados. Entretanto, no início do século XXI, não se tem mais a clareza sobre esta mesma distribuição de poder.

Conforme Celso Lafer, o sistema internacional atual está estruturado em "polaridades indefinidas".

\begin{abstract}
No pós Guerra Fria definiram-se temas que passam a constituir o corpo hegemônico das politicas legitimas, em tese ao discurso das potencias ocidentais (EUA, Europa e pela aliança, o Japão) aos países que adotaram valores ocidentais, como os latino-americanos. Temas como DH e democracia, problemas humanitários, liberdade econômica e criação de condições iguais de competição, combate ao narcotráfico, ao crime organizado, a solução multilateral de crises regionais, defesa do meio ambiente, etc. definem um espaço de disputa de interpretações. (LAFER, 2001, p 209).
\end{abstract}

Há indícios que se está no fim de uma era, o fim da modernidade que começou simbolicamente conforme Dussel, em 1492, e agora o fim desta hegemonia cultural europeia, substituída, talvez, pelos Brics: Brasil, Rússia, Índia, China e África do Sul, os novos atores do cenário global econômico, inclusive militar; ou ainda pelos povos colonizados do Sul que passam 
a refletir sobre suas raízes e cultura; marcando esse sistema multicultural.

No sistema mundo atual, o qual estamos adaptados e regidos, estamos acomodados a valores não democráticos, ou supostamente "democráticos" como no Brasil e não igualitários, apesar da aposta retórica da defesa da democracia e da igualdade entre os povos e nações.

Por fim, WALLERSTEIN faz uma reflexão sobre a busca de um universalismo que não seja europeu, mas sim universal ou global, diríamos um universalismo universal, onde fosse possível uma real troca de conhecimentos. "O que seria preciso, no século XXI, para chegar a um mundo onde não seja mais o Ocidente que dá e o resto que recebe, um mundo no qual o Ocidente veste a capa da ciência e o resto fica relegado a povos de temperamento mais "artístico/emocional"? (WALLERSTEIN, 2007, p. 119)

A luta entre o universalismo europeu e o universalismo universal é a luta ideológica central do mundo contemporâneo e o resultado será fator importantíssimo para determinar como será estruturado o sistema-mundo futuro, no qual entraremos nos próximos vinte e cinco a cinquenta anos. (WALLERSTEIN, 2007, p. 27)

Seria possível um universalismo universal em que todos tivessem as mesmas concepções e valores baseados na real igualdade dos seres humanos?

Um espaço político aberto e permanente de discussões entre os diversos povos do mundo a fim de se pensar a dignidade da pessoa humana e desta forma iniciar um processo de criação de direitos que poderíamos chamar de universais.

Permanece uma pergunta da qual não há uma resposta simples ou um caminho específico a ser trilhado; a ideia da institucionalização deste universalismo efetivamente universal como uma alternativa a se pensar.

\section{CONSIDERAÇÕES FINAIS}

A chamada "modernidade" ocultou as diversas culturas do mundo e permanece encobrindo de forma hegemônica suas verdadeiras raízes, apresentando aos povos uma sociedade plural de "fachada", que dificulta o florescer da diversidade e reconhece apenas a civilidade dos brancos, europeus.

Neste limiar do século XXI, importante se faz uma desocultação de identidades, de ideologias, um novo olhar sobre o indivíduo renasce de forma avassaladora. Ao mesmo tempo, que vivenciamos tendências racistas, segregadoras de raça, gênero, sexo, classe social, cidadania descortina-se a realidade da heterogeneidade, a realidade das diferenças, da diversidade.

Desconhecemos o futuro, mas sabemos que $\mathrm{o}$ mundo nunca esteve tão alerta às diversidades e ao diálogo como agora. Faz-se emergencial uma compreensão dessas diferenças, de forma a reconhecer, ouvir, agregar, aprender, para, quem sabe, conviver pacificamente com essa diversidade que é deslumbrante, enriquecedora, histórica e natural.

\section{REFERÊNCIAS}

AZEVEDO, Luiz Henrique Cascelli. Ius Gentium em Francisco de Vitória. A fundamentação dos Direitos Humanos e do Direito Internacional na tradição tomista. Porto Alegre: Ed. Sergio Antônio Fabris, 2008. 
DUSSEL, Enrique. 1492 - O Encobrimento do Outro - A Origem do "mito da modernidade”. Petrópolis: Vozes, 1993.

CANNON, Walter. Voodoo Death. American Journal of Public Health, 2002. Disponível em: <https://www.ncbi.nlm.nih.gov/pmc/articles/PMC1447285/>. Acesso em: 01/08/2017.

FRANÇA, Waldir Xavier. Disponível em: <http://pesformosos.com/o-que-e-missao-transcultural/> . Acesso em: 10 de outubro de 2013.

HUNTINGTON, Samuel. O Choque de Civilizações e a recomposição da ordem mundial. Tradução de M. H. C. Côrtes. Rio de Janeiro: Editora Objetiva, 1997.

LAS CASAS, Bartolomé de. Brevíssima relação da destruição das Indias - O paraíso destruído: a sangrenta história da conquista da América espanhola. Tradução de Heraldo Barbuy. Porto Alegre: L\&PM, 1991, 5a.edição.

LANDER, Edgardo. Ciências Sociais: saberes coloniais e eurocêntricos. In: LANDER: Edgardo (Org.). A colonialidade do saber: eurocentrismo e ciências sociais. Perspectivas latino-americanas. Colección Sur Sur. Buenos Aires: CLACSO, 2005.

LAFER, Celso. A Reconstrução dos Direitos Humanos - um diálogo com o pensamento de Hannah Arendt. Rio de Janeiro: Cia das Letras, 2001.

MAGAlHÃES, José Luis Quadros. Estado Plurinacional e Direito Internacional. Coleção para entender. Coordenação de Leonardo Nemer Caldeira Brant. Curitiba: Juruá, 2012.

MALDONADO-TORRES, Nelson. A topologia do ser e a geopolítica do conhecimento. Modernidade, império e colonialidade. In: SOUZA SANTOS, Boaventura; MENESES, Maria Paula (Orgs.). Epistemologias do Sul. São Paulo: Cortez, 2010.

MENESES, Maria Paula G. Corpos de Vilência, Linguagens de Resistência: as complexas teias de conhecimentos no Moçambique Contemporâneo. In: SOUZA SANTOS, Boaventura; MENESES, Maria Paula (Orgs.). Epistemologias do Sul. São Paulo: Cortez, 2010.

MILLS, Charles. PATEMAN, Carole. 2007. Contract and Domination. Malden, MA: Polity Press, 2007.

MORIN, Edgar. A Religação Dos Saberes. O desafio do século XXI. Rio de Janeiro: Bertrand Brasil, 2005.

QUIJANO, Aníbal. Colonialidade do poder, eurocentrismo e América Latina. In: LANDER: Edgardo (Org.). A colonialidade do saber: eurocentrismo e ciências sociais. Perspectivas latino-americanas. Colección Sur Sur. Buenos Aires: CLACSO, 2005.

. Colonialidade do poder e classificação social. In: SOUZA SANTOS, Boaventura; MENESES, Maria Paula (Orgs.). Epistemologias do Sul. São Paulo: Cortez, 2010.

PETIT, Carlos. Colônia. Cadernos de Pós-Graduação em Direito PPGDir./UFRGS, v. 10, n.2, 2015. 
RUIZ, Rafael. Francisco de Vitória e os direitos dos índios americanos. Porto Alegre: Ed. PUCRS, 2002.

SANCHES, Silvana Colombelli Parra. Pressupostos para pensar a alteridade no ensino de artes visuais na educação básica em mato grosso do sul. 2013. Disponível em: $<$ http://www.google.com.br/url?sa=t\&rct=j\&q=\&esrc=s\&source=web\&cd=2\&ved=0CDcQFjAB\&ur l=http $\% 3 \mathrm{~A} \% 2 \mathrm{~F} \% 2 \mathrm{Fperiodicos}$ uems.br\%2Fnovo\%2Findex.php\%2Finterfaces $\% 2$ Farticle\%2Fdownlo ad\%2F1289\%2F839\&ei=DhlXUpHCKO_B4AOXjIHAAQ\&usg=AFQjCNFPVdu_cbwkd9i_EqF69GBOXDTrw\&bvm=bv.53760139,d.dmg>. Acesso em: 10 out. 2013.

SOUZA SANTOS, Boaventura; MENESES, Maria Paula (Orgs.). Epistemologias do Sul. São Paulo: Cortez, 2010.

VITÓRIA, Francisco de. Os índios e o direito da guerra: de indis et de jure belli relectiones. Rio Grande do Sul: Unijuí, 2006.

- "Releituras" sobre os títulos legítimos pelos quais os Índios podiam ser sujeitos ao poder dos espanhóis. In: SUESS, Paulo (Coord.) A Conquista Espiritual da América Espanhola. Petrópolis:

Vozes, 1992.

WALTER, D. Mignolo. A colonialidade de cabo a rabo: o hemisfério ocidental no horizonte conceitual da modernidade. In: LANDER: Edgardo (Org.). A colonialidade do saber: eurocentrismo e ciências sociais. Perspectivas latino-americanas. Colección Sur Sur. Buenos Aires: CLACSO, 2005.

WALLERSTEIN, Immanuel. O Universalismo Europeu: a retórica do poder. São Paulo: Editora Boitempo, 2007.

Recebido em: 24/04/2017

Aceito em: 15/12/2017 
